\title{
Internal Intercostal Muscle
}

National Cancer Institute

\section{Source}

National Cancer Institute. Internal Intercostal Muscle. NCI Thesaurus. Code C32848.

Eleven pairs of skeletal muscle located between the ribs, which occupy the middle layer in the intercostal space, and function to move the ribs inferiorly. 